\title{
Age and learning environment: Are children implicit second language learners?*
}

\author{
KAREN LICHTMAN \\ Northern Illinois University, USA \\ (Received 31 October 2014-Revised I6 Fuly 2015-Accepted 24 September 2015- \\ First published online 26 February 20I6)
}

\begin{abstract}
Children are thought to learn second languages (L2s) using primarily implicit mechanisms, in contrast to adults, who primarily rely on explicit language learning. This difference is usually attributed to cognitive maturation, but adults also receive more explicit instruction than children, which may influence their learning strategies. This study crosses instruction condition with age, teaching forty children aged $5 ; 3$ to 7; I and forty adults an artificial mini-language under implicit or explicit training conditions. Participants produced novel sentences and judged sentence grammaticality equally well in either condition, but both children and adults in the explicit training condition developed greater awareness of the mini-language's structures - and greater awareness was associated with better performance for both age groups. Results show that explicit instruction affects children and adults in the same way, supporting the hypothesis that age differences in implicit vs. explicit L2 learning are not exclusively caused by maturation, but also influenced by instruction.
\end{abstract}

\section{INTRODUCTION}

When it comes to long-term attainment in second language (L2) learning, children have the advantage over adults: the younger a child is when the L2 acquisition process begins, the more likely that learner is to reach a successful outcome in the new language (Krashen, Scarcella \& Long, I982; Singleton \& Ryan, 2004). Second language learners who begin exposure to the $\mathrm{L}_{2}$ before age seven are able to reach an ultimate

\footnotetext{
* This research was supported by National Science Foundation Linguistics program grant BCS-II22629. Many thanks to all of the after-school program staff, parents, and students who helped with the study; research assistant Jeremy Schmidt; and Tania Ionin, Silvina Montrul, Melissa Bowles, and Pam Hadley for their input. Address for correspondence: Karen Lichtman, Department of Foreign Languages \& Literatures, Northern Illinois University, DeKalb, IL 6or r 5. e-mail: klichtman@niu.edu
} 
proficiency within the range of native speakers (Johnson \& Newport, I989). This aptitude for language learning is found at a time when children's cognitive functions are not yet fully developed. Why should adults, with more knowledge about language, study skills, and cognitive ability, be unable to learn languages as completely as children can?

One common explanation is that children and adults use different learning mechanisms: specifically, children use more implicit language learning mechanisms and adults use more explicit learning mechanisms (DeKeyser, 2000, 2003; DeKeyser, Alfi-Shabtay \& Ravid, 2010; DeKeyser \& Larson-Hall, 2005; Ellis, 2005, 2009; Muñoz, 2006; Paradis, 2004, 2009; Ullman, 200I). Implicit language learning happens unintentionally and without awareness on the part of the learner, when the learner is exposed to language input (Ellis, 2009). The knowledge resulting from implicit learning can be accessed quickly and automatically, even under time pressure (Ellis, 2005) - in short, the type of language knowledge that is useful for having a conversation. In contrast, explicit learning "is necessarily a conscious process and is generally intentional as well" (Ellis, 2009, p. 7). Explicitly learned knowledge includes metalinguistic rules, and can be accessed only when time is available and the learner's attention is on accuracy (Ellis, 2005) - in other words, the sort of conditions that exist when taking a test or editing writing. Because automatized, implicit knowledge can be accessed more quickly and with less draw on cognitive resources, it is often considered more desirable and more important for everyday language functions than explicit knowledge (Paradis, 2004). However, because it results from processing large amounts of input, implicit knowledge takes longer to acquire than explicit knowledge (DeKeyser, 2003). Implicit and explicit learning are not mutually exclusive-both types of learning certainly play a role in language acquisition, although learners may favor one or the other type of learning at different ages and in different instructional contexts (Muñoz, 2006).

There is a large body of evidence showing that adults are able to learn languages explicitly (Norris \& Ortega, 200I; Spada \& Tomita, 2010). Adults have been shown to master specific grammatical structures more quickly and accurately when given explicit instruction, even if this instruction takes place only over a short treatment time. In contrast, children are widely considered to use implicit language learning mechanisms (DeKeyser, 2003; DeKeyser \& Larson-Hall, 2005; Montrul, 2008; Muñoz, 2006; Paradis, 2004; Schmidt, I994). This view is part of the basic fabric of linguistic theory on age differences in L2 learning. Child language learning is said to be "automatic acquisition from mere exposure to a given language" (Lenneberg, I967); it is "not under learner control” (Bley-Vroman, I990). Moreover, children have been described as able to use ONLY implicit learning mechanisms (and adults only explicit 
problem-solving skills): "language acquisition from mere exposure (i.e., implicit learning), the only mechanism available to the young child, is severely limited in older adolescents and adults" (DeKeyser \& Larson-Hall, 2005 , p. 89). I refer to this position as the MATURATIONAL HYPOTHESIS: the idea that children rely primarily on implicit language learning mechanisms because they are maturationally constrained to rely mostly on implicit learning-and, that adults rely primarily on explicit language learning mechanisms because they are maturationally constrained to explicit learning. Some authors present a more nuanced version of this perspective. Bialystok ( I994) believes that knowledge continues to become more explicit over the course of the entire lifespan, Ullman (200I) allows that $\mathrm{L}_{2}$ learners may be able to increase their use of procedural memory of linguistic structures through more language experience, and Paradis (2004) sees implicit memory as important throughout lifespan, but explicit memory as emerging later and declining earlier. And, in time-limited research studies-even when tasks are intended to tap implicit knowledge - children have not always been shown to have an advantage over adults (Ferman \& Karni, 2010). Nonetheless, the concept of age effects for implicit language learning is so widely accepted that the presence of age effects, in and of itself, has been incorporated as part of the definition for implicit learning, and taken as evidence for implicit learning (Ellis, 2005; Paradis, 2004).

Where does the maturational hypothesis come from? It is not drawn from direct studies of children, as research on implicit and explicit learning has been carried out almost exclusively with adults (Ellis, 2005, 2009; Norris \& Ortega, 200I; Spada \& Tomita, 2010). Some studies make claims about children's learning processes by testing adults who began acquiring languages at different ages (e.g., Ellis, 2005), although such comparisons generally find only modest support for differing levels of implicit vs. explicit knowledge based on the initial age of acquisition. Studies directly investigating child $\mathrm{L}_{2}$ acquisition predominantly use tasks tapping implicit knowledge, such as free oral production (e.g., Blom, 2008; Ferman \& Karni, 2010; Jia \& Fuse, 2007; Unsworth, 2005; Zdorenko \& Paradis, 20II). Additionally, these studies often examine naturalistic child L2 learners, who are not directly comparable to instructed adult L2 learners because they typically receive much greater amounts of language input the number of years of classroom instruction that would equal ten years of language immersion would extend well beyond a lifetime (Muñoz, 2008).

The initial age of acquisition, though, is not the only difference between successful child language learners and unsuccessful adult language learners. Children also experience a different learning environment from adults and older adolescents. Child second language learning is defined as starting exposure to a second language between ages four and seven 


\section{I C H T M A N}

(Schwartz, 2004). In a naturalistic setting, children receive large amounts of input if they are schooled in the second language, hear simplified messages from caregivers, and have the option of remaining silent if they are not yet comfortable speaking. In contrast, adults are expected to speak, and may not receive input at a level they can understand (Krashen et al., I982). Additionally, younger immigrants self-select a richer L2 environment, including more L2 use with peers, media, and in the home, and thus receive much more input than older immigrants (Jia \& Aaronson, 2003; Jia \& Fuse, 2007).

Even in a foreign language classroom setting, adults and children experience different environments. In a variety of classroom learning contexts, there is a strong tendency towards language instruction for children being more implicit than language instruction for adults (Harley, Howard \& Hart, I 998; Muñoz, 2006). Because children supposedly rely on implicit learning mechanisms, teachers are told to avoid teaching grammatical rules to children: "Rules make sense to adults; they make little difference to young children" (Bialystok, I 994, p. 565). Curtain and Dahlberg (2010), a prominent textbook for foreign language teaching methods in elementary schools, asserts that "Children learn new languages best when ... Students learn grammar in context, through usage and not through analysis. Grammar for its own sake is not the object of instruction” (p. xxi). Child language instruction tends to focus on whole-language activities such as songs, games, and stories. In contrast, instruction for learners age twelve and up is characterized by form-focused activities and explicit teaching of the linguistic system (Torras, Navés, Luz Celaya, \& Pérez-Vidal, 2006, p. I78). Instruction for older learners typically includes explicit rule induction, extensive exposure to written language, and error correction.

The differences in typical classroom instruction between children and older learners create a chicken-and-egg problem that is at the heart of the present study: Do children learn languages implicitly because they are children, or do they learn languages implicitly because they have only been exposed to implicit language instruction? Adult language learners develop higher degrees of metalinguistic understanding of structures when given more explicit instruction (Rosa \& Leow, 2004; Rosa \& O’Neill, I 999). Older children also quickly develop more explicit second language knowledge when given small amounts of explicit instruction (Lichtman, 20I3). The fact that children typically receive less explicit instruction than adults, coupled with the finding that explicit instruction does increase metalinguistic knowledge, gives rise to what I will call the INSTRUCTIONAL HYPOTHESIS: children rely primarily on implicit language learning mechanisms because they are taught implicitly. Adults, on the other hand, rely primarily on explicit language learning mechanisms because they are taught explicitly. 
The clearest way to examine children's implicit and explicit language learning capabilities is to test how children learn under different types of instruction. Very few such studies exist. Swisher and Restrepo (r 995) used implicit and explicit instruction to teach four- to six-year-old children a novel grammatical marker; children were able to learn the marker in both the implicit and the explicit training condition. Finestack and Fey (2009) found that six- and seven-year-olds learned a novel marking better when they received explicit instruction. In a classroom setting, Harley et al. ( 1998 ) tested an explicit intervention targeting grammatical gender on a group of seven- to eight-year-olds who received otherwise implicit French immersion instruction. The experimental group-but not the control group-improved on comprehension of grammatical gender, both immediately and on a delayed post-test. While these studies target only isolated structures rather than a whole language, the results are not consistent with the idea that children can only learn language implicitly. Indeed, children learn many things about their native language quite explicitly in school - in particular, how to write it, which is one of the reasons that explicit (first) language knowledge increases dramatically when children start school (Birdsong, I989). However, this is rarely acknowledged in the field of second language acquisition, which has often focused on age - specifically, age of (initial) acquisition - as a crucial factor in determining to what degree implicit language learning processes will be used (DeKeyser, 2003; DeKeyser et al., 2010; DeKeyser \& Larson-Hall, 2005; Ellis, 2005; Muñoz, 2006). Age, though, covaries with learning environment, and when the learning environment is carefully measured, it can be a more predictive factor than age in determining L 2 outcomes (Jia \& Aaronson, 2003; Jia \& Fuse, 2007).

In order to make claims about children as categorically more implicit language learners than adults, we need to examine their language learning under controlled instruction conditions (Ferman \& Karni, 2010). One way to do this is through instruction in an artificial mini-language (de Graaf, I 997; DeKeyser, I 995; Ferman \& Karni, 2010; Morgan-Short, 2007). The advantages of using an artificial mini-language paradigm are that participants can reach high proficiency within a short period of time, and exposure to the language can be completely controlled because the participants will not be exposed to the language outside of the experiment. Results of artificial mini-language studies testing adults in different instruction conditions generally show an advantage for explicit instruction (de Graaf, I997; DeKeyser, I995); although if enough time is allowed for participants to gain proficiency through processing a mini-language to complete a task, implicitly and explicitly trained participants may perform equally well (Morgan-Short, 2007; Morgan-Short, Sanz, Steinhauer \& Ullman, 2010). 


\section{I C H T MAN}

By holding the learning environment constant through an experimental study, the independent effects of age on second language learning and metalinguistic understanding can be directly investigated. The present study crosses age with implicit and explicit instruction conditions. Implicit instruction uses communication-oriented activities to allow free use of the target forms in context, without the use of metalanguage (Housen \& Pierrard, 2006). It does not include rule presentation or directions to attend to specific forms (Norris \& Ortega, 200I). Explicit instruction, on the other hand, includes rule explanation, is obtrusive, presents the target forms in isolation, and involves controlled practice of the target forms (Housen \& Pierrard, 2006). The present study teaches child and adult participants an artificial mini-language under the same controlled implicit or explicit instruction conditions. This allows investigation of the following research questions:

RQI: How does implicit vs. explicit instruction affect children's and adults' LEARNING of the grammatical structures of an artificial mini-language?

RQ2: How does implicit vs. explicit instruction affect children's and adults' AWARENESS of the grammatical structures of an artificial mini-language?

$\mathrm{RQ}_{3}$ : Is greater awareness of the grammatical structures of an artificial minilanguage associated with higher performance for children? For adults?

RQ4: Is age within the child group and within the adult group associated with higher performance on the grammatical structures of an artificial mini-language? With greater awareness of those structures?

If, as the maturational hypothesis holds, children are primarily implicit language learners, then we would expect that children will benefit more from implicit than explicit instruction (RQI), fail to develop awareness of the mini-language's structures in either condition $\left(\mathrm{RQ}_{2}\right)$, produce the mini-language equally well independently of their awareness of structure $\left(\mathrm{RQ}_{3}\right)$, and perhaps develop greater awareness of structure and more accurate performance as they get older $\left(\mathrm{RQ}_{4}\right)$. The instructional hypothesis, on the other hand, predicts that instruction condition will be the primary determinant of implicit vs. explicit language learning. In this case, children may learn the mini-language better under explicit training (RQI), will develop awareness of structure if they are given explicit training $\left(\mathrm{RQ}_{2}\right)$, may perform better when they have greater awareness of structure $\left(\mathrm{RQ}_{3}\right)$, and should not develop markedly different awareness or performance patterns according to within-group age $\left(\mathrm{RQ}_{4}\right)$.

\section{METHOD}

\section{Participants}

Forty child participants aged five to seven were recruited from after-school programs at public schools in the United States. Age four to seven is 
considered to be the canonical starting age for child L2 acquisition, because the first language is already in place by age four, but nativelike ultimate attainment in an L2 can be found in learners starting as late as age seven (Johnson \& Newport, I 989; Schwartz, 2004). Forty adult participants were recruited through a university website.

Both children and adults were only eligible to participate in the study if they were native English speakers and had not studied any foreign language for longer than two years, since well-developed learning strategies adopted for other languages may influence participants' experience of the instructional conditions. This selection criterion was stricter than those of other studies, some of which do not limit or report the amount of prior language instruction (DeKeyser, I995); whereas others report participants with as many as five years of prior instruction (Morgan-Short, 2007). Despite restricting participants to less than two years of prior instruction, the two age groups in the present study differed, unintentionally, with respect to the number of years of foreign language instruction they had had: the adults had had an average of $\mathrm{I} \cdot 5$ years of previous language instruction $(S D=0 \cdot 66)$, whereas the children had had an average of only 0.34 years of language instruction $(S D=0.57)$.

Within each age group, twenty participants were assigned to implicit instruction and twenty participants were assigned to explicit instruction. Assignment was done pseudo-randomly, so that within each age group, the implicit and explicit instruction conditions would be balanced for the demographic variables of gender, age, foreign language experience, grade or degree year, education (or parents' education, for children), and scaled Peabody Picture Vocabulary Test score (Dunn \& Dunn, 2007) as a measure of native language performance (see Table I).

\section{Mini-language: Sillyspeak}

The artificial mini-language, Sillyspeak, is adapted from Hudson Kam and Newport's (2009) Experiment 3, since that mini-language was successfully learned by both children with an average age of 5; Io, and adults. The version of the language used in the present study has four verbs (two transitive: mert 'move' and gern 'fall,' and two intransitive: flim 'hit' and prag 'go inside of'), two determiners ( $p o$ for feminine nouns and $k a$ for masculine), and twelve nouns (feminine ferluka 'girl', nagra 'woman', fumpoga 'bird', nerk 'frog', rungmat 'ball', and blifin 'truck', and masculine mernat 'boy', dilba 'man', ladna 'turtle', blaga 'bear', melnag 'car', and flerbit 'cup'), for a total of ninety-nine semantically possible sentences. Following Hudson Kam and Newport (2009), the sentences were acted out with toys for all participants. 
TABle I. Participant demographic information

\begin{tabular}{|c|c|c|c|c|}
\hline & \multicolumn{4}{|l|}{ Group } \\
\hline & \multicolumn{2}{|l|}{ Child } & \multicolumn{2}{|l|}{ Adult } \\
\hline & Implicit training & Explicit training & Implicit training & Explicit training \\
\hline$N$ (male/female) & $20(9 /$ I I $)$ & $20(9 /$ I I $)$ & $20(10 / 10)$ & $20(8 / 12)$ \\
\hline Age & $\begin{array}{l}6 ; 10(0 ; 9) \\
5 ; 5-7 ; I I\end{array}$ & $\begin{array}{l}6 ; 7(0 ; 10) \\
5 ; 3-7 ; 9\end{array}$ & $\begin{array}{l}24 ; 10(8 ; 3) \\
I 8-5 I\end{array}$ & $\begin{array}{l}23 ; 7(7 ; 10) \\
I 8-5 I\end{array}$ \\
\hline Years language instruction & $\begin{array}{l}0.3(0 \cdot 5) \\
0-2\end{array}$ & $\begin{array}{l}0.4(0 \cdot 6) \\
0-2\end{array}$ & $\begin{array}{l}\mathrm{I} \cdot 6(0 \cdot 6) \\
0 \cdot 5^{-2}\end{array}$ & $\begin{array}{l}\mathrm{I} \cdot 5(0 \cdot 7) \\
O-2\end{array}$ \\
\hline $\begin{array}{l}\text { Grade (children)/ } \\
\text { Years out of school (adults) }\end{array}$ & $\begin{array}{l}\text { I.I (०.9) } \\
K-2\end{array}$ & $\begin{array}{l}\mathrm{I} \cdot \mathrm{O}(\mathrm{I} \cdot \mathrm{O}) \\
K-2\end{array}$ & $\begin{array}{l}3 \cdot I(3 \cdot 7) \\
O-I 5\end{array}$ & $\begin{array}{l}3 \cdot 3(3 \cdot 6) \\
O-I 4\end{array}$ \\
\hline Scaled PPVT score & $\begin{array}{l}\text { I I } 3 \text { (I } 2) \\
92-I 4 O\end{array}$ & $\begin{array}{l}\text { Iо8 (го) } \\
93-124\end{array}$ & $\begin{array}{l}\text { I07 (12) } \\
80-130\end{array}$ & $\begin{array}{l}\operatorname{I} 08(9) \\
9 I-I 27\end{array}$ \\
\hline Median (parents') education & $\begin{array}{l}\text { 4-year college } \\
\text { some college-grad/prof }\end{array}$ & $\begin{array}{l}\text { 4-year college } \\
2 \text {-year college-grad/prof }\end{array}$ & $\begin{array}{l}\text { High school } \\
\text { high school-grad/prof }\end{array}$ & $\begin{array}{l}\text { High school } \\
\text { high school-grad/prof }\end{array}$ \\
\hline
\end{tabular}

NOTES: Each cell includes the mean, standard deviation in parentheses, and range in italics unless otherwise specified. $\mathrm{K}=$ kindergarten. PPVT $=$

Peabody Picture Vocabulary Test. The scale for education is high school, some college, 2-year college, 4-year college, graduate/professional degree. 
The two grammatical rules governing the mini-language are: (I) word order is VSO; and (2) half the nouns are feminine (including 'girl' and 'woman') and half the nouns are masculine (including 'boy' and 'man'). Each grammatical gender includes two human, two animal, and two inanimate nouns: 'bird', 'frog', 'ball', and 'truck' were feminine, and 'turtle', 'bear', 'car', and 'cup' were masculine.

\section{Overall procedure}

Following Hudson Kam and Newport (2009), learners participated in seven sessions of about I 5 minutes each in length, over the course of ten days. Participants were run individually for the first session, during which the researchers explained the study, exposed the participants to the Sillyspeak vocabulary list, and administered the Peabody Picture Vocabulary Test. For sessions 2-6, participants were run in groups of two or three. Participants were taught the Sillyspeak grammar rules each day if they were in the explicit condition, and participants in both conditions were exposed repeatedly to the set of Sillyspeak study sentences. On the last day, participants were asked to recall as many vocabulary words as they could. They then completed two production tests, a grammaticality judgment test, and a series of debriefing questions.

Day $I$. On the first day, all subjects were exposed to the vocabulary list four times (without translation) and asked to repeat the words. The researcher demonstrated actions for the four verbs, which the participants repeated while saying the verbs. Learners then repeated the labels of the twelve nouns as the toys were presented. Nouns were presented without articles during each exposure to the vocabulary list, in order to provide evidence that the noun-article unit was not a single word.

Days 2-6. Hudson Kam and Newport (2009) used only implicit sentence exposure without rule presentation, so an additional explicit training condition was designed for the present study. The differences between the implicit and explicit training conditions were that the explicit condition included translation of the vocabulary list, a focus on 'the right way to say' the sentences, fewer exposures to the sentences in order to make time for rule instruction (DeKeyser, I995), and explicit rule instruction. On days 2-6, the explicit group was taught the two grammatical rules each day, using cue cards with pictures representing the rules (Ebbels, 2007). While studies with adults often present the rules only in the first session or only intermittently (DeKeyser, I995; Morgan-Short et al., 2010), rules were presented to the children and adults in the present study each day in order to maintain attention on explicit language information.

The rule for word order was contrasted with English: "In English, if you want to say 'The girl moves', you say 'the girl' first and then you say 'moves'. 


\section{I CHT MAN}

But in Sillyspeak, you say mert first and then you say ferluka po. So you say the action first, and then you say which toy is doing the action." The rule for word order was explained using pictures of the toys: "If you're talking about a girl or a woman, you have to use po. If you're talking about a boy or a man, you have to use $k a$. Po is for girls and $k a$ is for boys. We use po for ferluka (girl), nagra (woman), fumpoga (bird), nerk (frog), rungmat (ball), and blifin (truck). We use ka for mernat (boy), dilba (man), ladna (turtle), blaga (bear), melnag (car), and flerbit (glass)." The implicit training group never saw or heard the grammatical rules.

Both groups were exposed to a practice set of twelve intransitive and twelve transitive sentences, which they were asked to repeat while acting out the sentence with the toys, following the experimenter. In all, both groups were exposed to the vocabulary list twelve times, while the implicit group practiced the study sentences six times and the explicit group practiced the study sentences four times. Example intransitive (I) and transitive (2) study sentences are provided below.

(I) Gern rungmat po.

Falls ball the-F

'The ball falls.'

(2) Prag ladna ka blifin po.
Goes-inside turtle the-M truck the-F
'The turtle goes inside the truck.'

Day 7 . On the final day, the participants were tested individually on their knowledge of the mini-language. First, they were asked to recall as many vocabulary items as they could; these items were the only ones used for the subsequent tests.

Next, they completed two oral sentence production tests - the first designed to tap implicit language knowledge, and the second designed to tap more explicit knowledge. For the first test, the experimenter acted out novel sentences using the toys. Participants were simply instructed to say the whole sentence in Sillyspeak. Implicit design features of this test include time pressure (because it is oral), a focus on meaning, and not encouraging the use of rules or metalinguistic knowledge. Adults were tested on twelve novel sentences, and children were tested on five to eight novel sentences (in piloting the study, some children stopped participating before they had produced twelve novel sentences for each of the two tests).

For the second production test, subjects in both conditions were asked to produce the same sentences, but this time their attention was directed to both word order and determiners with the following directions: "This time I want you to pay attention to two things. First, make sure you're saying the words in the right order for Sillyspeak. Second, make sure you say po or $k a$ after every toy. Take your time and go slowly so you can 
think about the word order and think about whether you want to say po or $k a$." Since this second test introduced rules and metalinguistic knowledge to the same task and reduced the time pressure, it provides the closest possible comparison with the implicit production test, maintaining the same level of difficulty but tapping more explicit knowledge.

After the production tests, participants were asked to judge the grammaticality of sixteen sentences which were audio-recorded and played from a laptop computer. Half of the sentences were grammatical, and the other half tested either sensitivity to word order violations (correct Mert rungmat po vs. incorrect *Po rungmat mert for 'the ball moves') or sensitivity to article violations (correct Gern melnag ka vs. incorrect Gern melnag *po for 'the truck falls'). Judgments were made by selecting a happy face if the sentence sounded just like Sillyspeak, and a sad face if the sentence sounded different from Sillyspeak in any way. Testing language outcomes in two ways (oral production and sentence judgments) increases the reliability of the measure of participants' learning.

Finally, participants answered a series of debriefing questions, including "Did you think it was hard to learn Sillyspeak?", "Were you looking for rules or patterns in the sentences?", and "What do you think po and $k a$ mean?" Adults then completed a think-aloud task while reading five sentences in Sillyspeak containing a new noun, misna, which corresponded to a toy elephant. One of the adults' sentences used a different (incorrect) article for misna, providing an opportunity for them to verbalize their knowledge of the determiners. Children completed a shorter debriefing during which they were asked why one toy that they had used correctly in the production tasks was po versus $k a$, and chose an article for the novel noun misna, corresponding to a grandfather toy, showing whether they could generalize the rule about $p o$ vs. $k a$ to a new noun. Debriefing is important in studies using implicit vs. explicit training conditions because it is relatively common for participants to figure out grammatical rules even when given implicit training (e.g., DeKeyser, I995). The debriefing procedure was designed to give participants an opportunity to express any explicit knowledge they may have developed in more than one way: by explicitly describing rules or patterns, and by applying their knowledge of the rules to a novel noun.

RESULTS

$R Q_{I}$ : How does implicit vs. explicit instruction affect children's and adults' LEARNING of the grammatical structures of an artificial mini-language?

Learning of the artificial mini-language was measured using ( $\mathrm{I}$ ) the number of words recalled, (2) accuracy of word order on both production tests, (3) 


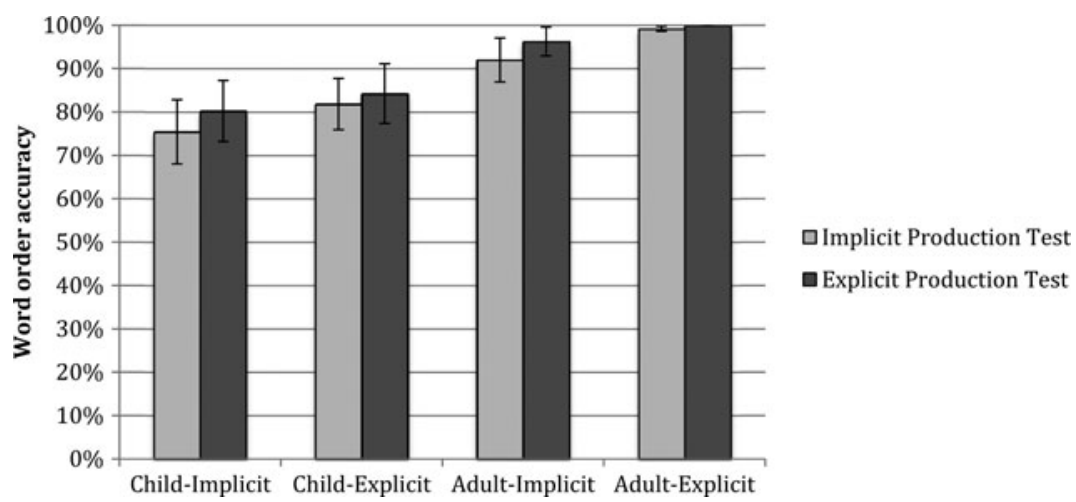

Fig. I. Accuracy of word order production on two tests by children and adults in implicit or explicit instruction conditions. Error bars represent standard error.

accuracy of articles on both production tests, and (4) accuracy at judging sentences on the grammaticality judgment task (GJT).

Number of words recalled was analyzed using a two-way ANOVA with two age groups (adults, children) and two instruction conditions (implicit, explicit) as between-subjects variables. Adults recalled more vocabulary words than children ( Iо-I I vs. 5-6; $F($ I, 79$)=67 \cdot 97, p<\cdot 00$ I,$\eta_{p}^{2}=.47$ ), but there was no effect of training condition $\left(F(\mathrm{I}, 79)=0.099, p=.753, \eta_{p}^{2}=.00 \mathrm{I}\right)$ and no interaction between age and training condition $(F(\mathrm{r}, 76)=3.75$, $p=.056, \eta_{p}^{2}=.05$ ). The number of words known was positively related to the other production test measures (word order and article correctness), so it was not the case that participants who remembered (and were therefore tested on) fewer words scored better on the other tasks. Two children (one in each group) could not remember any words and so did not participate in the production tests, and an additional child was excluded from the analysis because he did not participate in the second production test.

The production tests were scored for word order correctness and article correctness. Sometimes participants produced incomplete sentences. Word order was scored on an error-free basis: if the sentence contained at least a noun and one other word, it was marked as correct if no words were out of order, and incorrect if words were out of order. All groups did fairly well with production of word order, as shown in Figure I. Children produced $70-85 \%$ of sentences with correct word order, and adults produced $90-\mathrm{I} 00 \%$ of sentences with correct word order.

Accuracy of word order production was analyzed using a two-way ANOVA with age group and instruction group as between-subjects variables, and production test (first/implicit, second/explicit) as a within-subjects variable. There was a significant effect of age group $(F(\mathrm{I}, 73)=\mathrm{I} 2.7 \mathrm{I}$, 


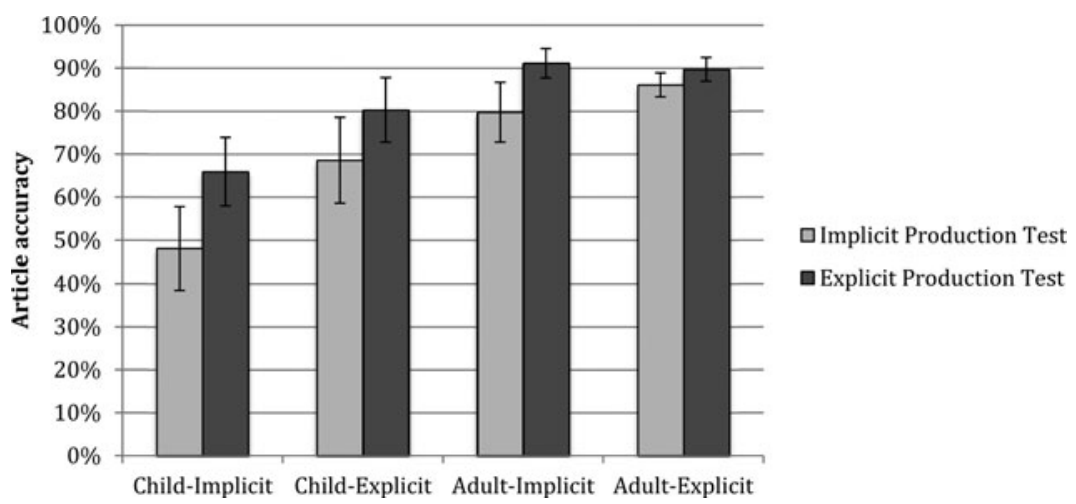

Fig. 2. Accuracy of article production on two tests by children and adults in implicit or explicit instruction conditions. Error bars represent standard error.

$\left.p=.00 \mathrm{I}, \eta_{p}^{2}=\cdot \mathrm{I}_{5}\right)$, since adults were more accurate than children, and a significant effect of test $\left(F(\mathrm{r}, 73)=4 \cdot 20, p=.04, \eta_{p}^{2}=.05\right)$, since all groups were more accurate on the second (explicit) production test, but no effect of training and no interactions.

Each noun produced by a participant was scored for article correctness as either correct, incorrect, omitted, or other (rarely, participants produced blends of the articles, such as *ko.)

Children produced correct articles $50-80 \%$ of the time, whereas adults produced correct articles $80-90 \%$ of the time, as shown in Figure 2. Additionally, all groups improved on article production when given more explicit instructions for the second production test ("make sure you say po or $k a$ after every toy"). Article production was analyzed using a two-way ANOVA with age group and instruction group as between-subjects variables, and test as a within-subjects variable. There was a significant effect of age group (adults were more accurate than children: $F(\mathrm{I}, 73)=\mathrm{I} 3.64, p<.00 \mathrm{I}$, $\eta_{p}^{2}=\cdot_{1} 6$ ), and a significant effect of test (all participants were more accurate on the explicit production test than the implicit: $F(\mathrm{I}, 73)=\mathrm{I} 8.93, p<.00 \mathrm{I}$, $\left.\eta_{p}^{2}=\cdot 2 \mathrm{r}\right)$, but no effect of training condition and no interactions.

The difference in article production scores between children and adults was largely driven by children's higher rate of omitting articles, particularly on the implicit production test. On the explicit production test, children omitted fewer articles and produced both more correct articles and more incorrect articles. Error rates were similar for masculine and feminine nouns, and for male, female, and inanimate nouns.

Average endorsement rates on the grammaticality judgment task were calculated for each type of sentence (grammatical, gender violation, and word order violation). Performance at ceiling would be ı००\% endorsement of grammatical sentences, and $\circ \%$ endorsement of both types of 


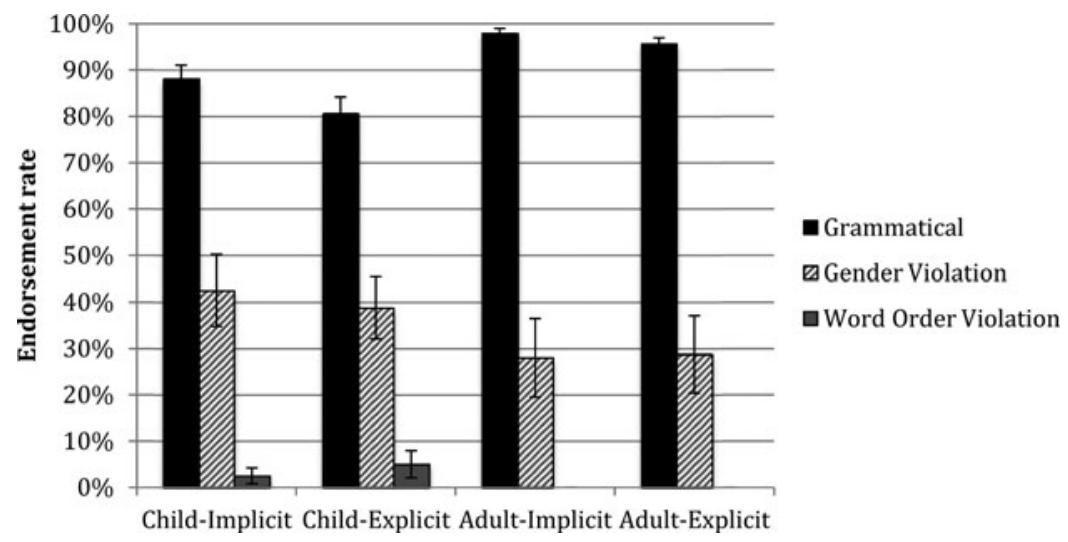

Fig. 3. Percentage of sentences (grammatical sentences, sentences with gender violations, and sentences with word order violations) endorsed as grammatical by children and adults in implicit or explicit instruction conditions. Error bars represent standard error.

ungrammatical sentences. Participants in all four groups were able to distinguish grammatical from ungrammatical sentences. All groups were good at accepting grammatical sentences and excellent at rejecting word order violations, with less consistent performance on rejecting article violations, as shown in Figure 3.

GJT ratings were analyzed using a two-way repeated measures ANOVA, with age group and training group crossed as between-subjects variables, and grammaticality (grammatical, ungrammatical) and sentence type (gender violation, word order violation) crossed as within-subjects variables. There was a significant effect of grammaticality $(F(1,76)=$ $\left.842.73, p<.001, \eta_{p}^{2}=.9 \mathrm{I}\right)$, since grammatical sentences were rated higher than ungrammatical sentences, and a significant effect of structure $\left(F(\mathrm{I}, 76)=50 \cdot 45, p<.00 \mathrm{I}, \eta_{p}^{2}=.40\right)$, since overall, sentences testing articles were rated more highly than sentences testing word order. There was also a significant interaction of grammaticality * age group $\left(F(1,76)=I_{7} \cdot 05\right.$, $\left.p<\cdot 0 \circ \mathrm{I} \eta_{p}^{2}=\cdot_{\mathrm{I}} 8\right)$, since adults distinguished between grammatical and ungrammatical sentences more strongly than children; and a significant interaction of structure * grammaticality $(F(\mathrm{I}, 76)=58.60, p<.00 \mathrm{I}$, $\left.\eta_{p}^{2}=\cdot 44\right)$, since grammaticality affected ratings of sentences testing word order more strongly than it affected ratings of sentences testing articles. There was no significant effect of age group (alone) or training group.

$R Q_{2}$ : How does implicit vs. explicit instruction affect children's and adults' AWARENESS of the grammatical structures of an artificial mini-language?

Debriefing was scored using the categories of NO REPORT, NOTICING, and understanding (e.g., Rosa \& Leow, 2004; Rosa \& O’Neil, i 999), based 


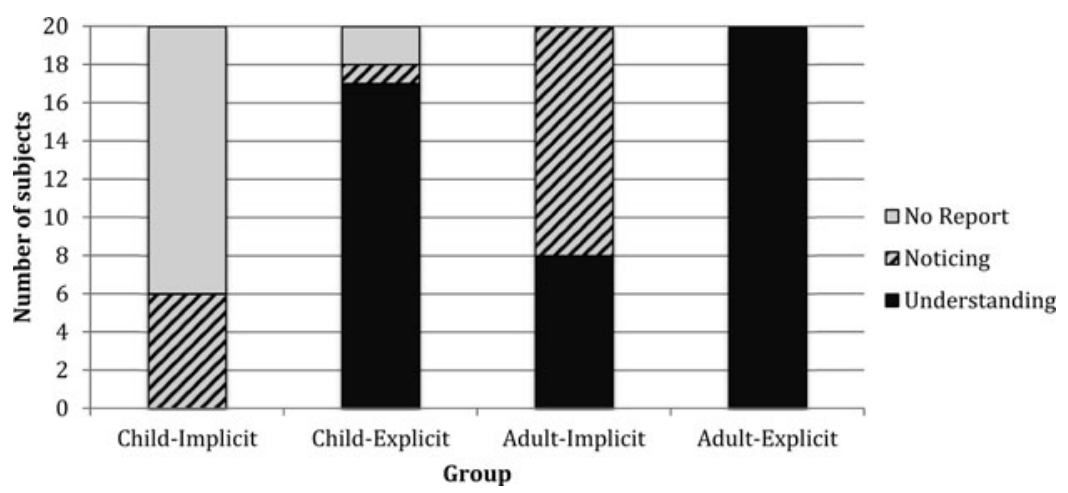

Fig. 4. Number of subjects in each age/instruction group who reached the awareness level of no report, noticing, or understanding the mini-language's grammatical structures.

on Schmidt's ( I 990) Noticing Hypothesis. Each participant's answers to the debriefing were coded as one of these three categories. In order to be categorized as no report, the participant had to make no reference to either word order or po and $k a$ during the debriefing (excepting the answer to the question "Would we call him misna po or misna ka?" for children, since the question forced the children to focus on $p o$ and $k a$ ). In order to be classified as noticing, the subject had to mention $p o$ and $k a$ or word order, but not formulate a correct rule explaining them. In order to be classified as understanding, the subject had to formulate correct rules; in the case of $p o$ and $k a$, the rule had to correctly refer to gender, not to an incorrect cue such as the verb or the color of the toy.

To give a qualitative impression of these levels of understanding, a sample child comment that was scored as no report was (in response to the question "Did you figure out any rules about Sillyspeak?") "Yes. If you get some wrong, it doesn't really matter." A comment that qualified as noticing was "I think I figured out one [rule]. Sillyspeak po and ka, I don't know if they have a difference or not, but they come with the word in front of it, and that's what it sounds like." A child comment that clearly qualified as understanding was "You say the action and then you say the toy, and then, uh, po is for girls and ka is for boys."

Figure 4 shows the number of participants in each group who fell into each category of awareness on the last day of the study. Two-thirds of the children in the Child-Implicit group fell into the no report category, but one third did notice the grammatical structures; no one in this group reached the level of understanding the structures. Most of the children in the Child-Explicit group, however, did reach the level of understanding the grammatical structures. In the Adult-Implicit group, slightly more than half of the adults noticed the structures, and slightly less than half developed 
TA B LE 2. Chi-squared test for categorical awareness level by instruction group

\begin{tabular}{lcccc}
\hline & \multicolumn{2}{l}{ Awareness level } & & \\
\cline { 2 - 4 } Instruction group & No report & Noticing & Understanding & Total \\
\hline Implicit & I $4(8)$ & I $8(9 \cdot 5)$ & $8(22 \cdot 5)$ & 40 \\
Explicit & $2(8)$ & I $(9 \cdot 5)$ & $37(22 \cdot 5)$ & 40 \\
Total & I6 & I9 & 45 & \\
\hline
\end{tabular}

NOTE: Expected numbers for each cell are given in parentheses.

TABLE 3. Chi-squared test for categorical awareness level by age group

\begin{tabular}{lcccc}
\hline & \multicolumn{2}{l}{ Awareness level } & & \\
\cline { 2 - 4 } Age group & No report & Noticing & Understanding & Total \\
\hline Child & I6 $(8)$ & $7(9 \cdot 5)$ & I $7(22 \cdot 5)$ & 40 \\
Adult & $\circ(8)$ & I2 $(9 \cdot 5)$ & $28(22 \cdot 5)$ & 40 \\
Total & I6 & I9 & 45 & \\
\hline
\end{tabular}

NOTE: Expected numbers for each cell are given in parentheses.

awareness at the level of understanding. No adults fell into the no report category. All the participants in the Adult-Explicit group reached the level of understanding. In other words, some adult participants in the implicit training condition developed explicit knowledge that they were not taught.

Statistically, there was a strong association between instruction condition and category of noticing $\left(\chi^{2}(2)=42 \cdot 90, p<\cdot 00 \mathrm{I}\right.$ ) (see Table 2 ). Participants in the explicit condition reached higher levels of understanding than participants in the implicit condition. There was also a significant association between age group and category of noticing (no report, noticing, or understanding) $\left(\chi^{2}(2)=\right.$ 20.005, $p<.00$ I) (see Table 3). Adults were more likely to reach the level of understanding the grammatical rules, and children were less likely to reach the level of understanding. Effect size for $2 \times 3$ chi-squared tests is calculated using Cramer's V (Larson-Hall, 2010): $0 \cdot \mathrm{I}$ is considered a small effect size, 0.3 a medium effect size, and 0.5 a large effect size. The effect size of instruction was $0 \cdot 27$, nearly a medium effect, while the effect of age was $0 \cdot 12$, a small effect. Both instruction and age influenced noticing, but instruction had a larger effect than age.

$R_{3}:$ Is greater awareness of the grammatical structures of an artificial mini-language associated with higher performance for children? For adults?

In order to simplify the dependent variable of performance on the mini-language so that it could be more easily compared to age and to 


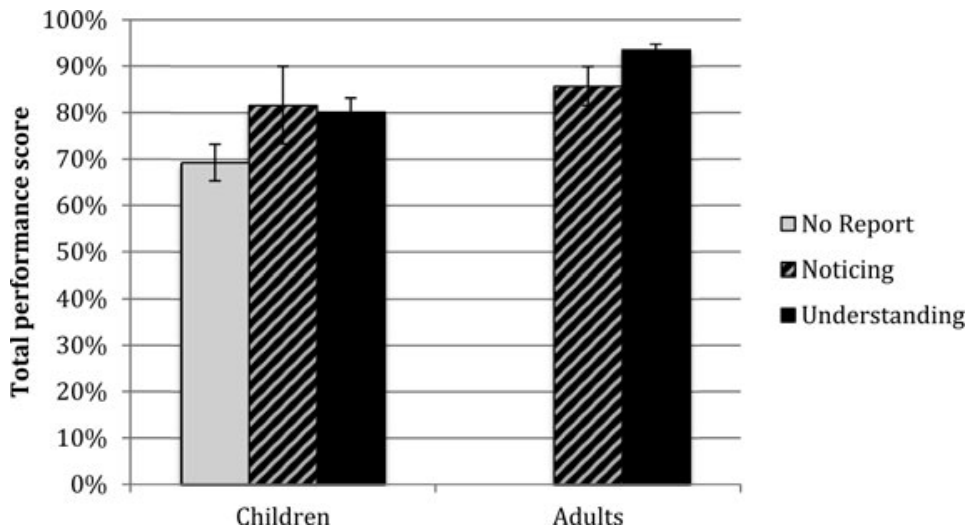

Fig. 5. Total language performance score of children and adults who reached the awareness level of no report, noticing, or understanding the mini-language's grammatical structures. Error bars represent standard error.

awareness, a total performance score for the production tasks and grammaticality judgment task together was calculated as follows: an average was taken of percentage of word order correctness on the implicit production test, percentage of word order correctness on the explicit production test, percentage of correct articles on the implicit production test (using the correct articles out of total nouns criterion), percentage of correct articles on the explicit production test (using the same criterion), percentage of grammatical items rated correctly on the GJT, and percentage of ungrammatical items rated correctly on the GJT. This yielded a total percentage score. Scores ranged from $43 \%$ to $98 \%$ for the children, and from $54 \%$ to I $00 \%$ for the adults.

Figure 5 shows total performance scores for each age group, subdivided into awareness groups. Total performance was analyzed using a two-way ANOVA with age group (adults, children) and awareness group (no report, noticing, understanding) as between-subjects variables. There was a significant effect of age group $\left(F(\mathrm{I}, 72)=5.36, p=.02, \eta_{p}^{2}=.07\right)$, and a significant effect of awareness group $\left(F(2,72)=3.49, p=.04, \eta_{p}^{2}=.09\right)$ on total performance, but no interaction between age group and awareness group $\left(F(\mathrm{I}, 72)=2.53, p=\cdot 12, \eta_{p}^{2}=.03\right)$. In other words, adults performed better than children and participants who understood the rules more fully performed better than those who were less aware, but awareness affected performance in the same way for both children and for adults. This result is of course partially driven by the fact that no adults finished the study in the no report group, but it is important to note that in the child group - as in the adult group-greater awareness was associated with better performance on the structures of the mini-language. 


\section{I CHT MAN}

RQ4: Is age within the child group and within the adult group associated with higher performance on the grammatical structures of an artificial mini-language? With greater awareness of those structures?

The last research question asked whether there were within-group age-related differences in total performance score, and in awareness. First, total performance scores were compared to age. The general pattern in the second language acquisition literature is that for instructed learners (as in the present study), starting language study at an older age is associated with faster improvement and better performance in the beginning stages of language acquisition (e.g., Krashen et al., I982; Muñoz, 2006). Correlations were computed for age on an individual basis as compared to total performance on the mini-language. For both child groups, age was positively related to total performance, but this correlation did not reach significance (Child-Implicit group $r(\mathrm{I} 6)=0.24, \quad p=\cdot \mathrm{I}_{7}$; Child-Explicit group $r(\mathrm{I} 7)=0.24, p=\cdot \mathrm{I} 6)$. Importantly, this is true of both the implicit and explicit training groups. For the adult groups, age was negatively related to total performance on the mini-language, but this correlation only reached significance for the Adult-Explicit group $(r($ I 8$)=-0 \cdot 68$, $p<\cdot 0 \circ$ I; Adult-Implicit group $\left.r(\mathrm{I} 8)=-0 \cdot 22, p=\cdot \cdot_{\mathrm{I}} 8\right)$.

Individual age was also examined as it related to awareness of the mini-language's structures, with no report, noticing, and understanding coded as 0 , I, and 2 respectively. Age was related to awareness in the Child-Explicit group (the few children who failed to learn the minilanguage's rules were younger: $r(\mathrm{i} 8)=0.47, p=.02)$. The other three groups did not have a significant relationship between age and awareness (Child-Implicit group $r(\mathrm{I} 8)=-0.04, \quad p=\cdot 43$; Adult-Implicit group $r($ I 8$)=-0.25, p=\cdot$ I 4 ; no correlation possible for Adult-Explicit group due to ceiling effects on awareness levels).

\section{DISCUSSION}

By assigning children and adults to controlled instructional conditions, this study was able to separately consider the effects of age and of the effects of instruction on learning and metalinguistic awareness of an artificial mini-language.

First, the study asked how implicit vs. explicit instruction affected children's and adults' learning of the language. Four different measures of performance (number of words learned, production of word order on implicit and explicit production tests, production of articles on implicit and explicit production tests, and a grammaticality judgment test) found no effect of training on performance in the mini-language. Participants in all conditions were able to learn the mini-language, generate original sentences, and distinguish between grammatical and ungrammatical 
sentences. All groups produced the language more accurately when asked to pay attention to the grammatical structures during the explicit production test, regardless of whether they had had any explicit instruction during the study sessions. All groups detected word order violations, which are more salient, better than article violations on the grammaticality judgment task. In terms of the behavioral measures in the study, the only difference between children and adults is a quantitative one-adults performed better. This is not surprising given the short duration of the study (seven I5-minute sessions), since adults are faster learners in the short term (Ferman \& Karni, 2010; Krashen et al., 1982; Singleton \& Ryan, 2004.)

Second, the study asked whether implicit vs. explicit instruction would affect children's and adults' awareness of the grammatical structures of the mini-language. Here, differences between training groups appeared. Children, by and large, followed their instructional conditions: the majority of implicitly instructed children did not notice the grammatical structures of the language, and the majority of explicitly instructed children understood and applied the rules of the language. This supports the instructional hypothesis, since children were able to become explicitly aware of the language's structures.

The explicitly instructed adults also followed their condition; all of them reached the level of understanding the grammar rules of the language. However, the implicitly instructed adults did not always perform according to their instruction condition: all of them at least noticed the grammatical structures of the language, and almost half of them were able to formulate accurate rules about the language. Those adults who did develop explicit knowledge even in the implicit condition performed near ceiling on the production tasks.

Adults developing explicit knowledge even in implicit training conditions is a common finding in research on instruction conditions (DeKeyser, I 995; Ferman \& Karni, 2010; Morgan-Short, 2007). Rather than being considered a flaw in the experimental design, the fact that adults are able to 'spontaneously' develop explicit knowledge in implicit training conditions should be considered a characteristic of adult language learning. The results of the present study suggest that this may constitute a qualitative difference from the learning of children, since children did not develop explicit knowledge in the implicit training condition, providing support for the maturational hypothesis.

However, this study cannot determine whether the result that implicitly trained adults (but not children) developed explicit awareness was caused by maturation, or by prior language instruction (or by both), because the adults had had more previous instruction in a foreign language than the children. Each training group within each age group was balanced for years of prior foreign language experience, and both children and adults 


\section{I CH T M A N}

were excluded from participating in the study if they had more than two years of foreign language instruction. All four age/training groups included participants with the full possible range of $0-2$ years prior language instruction. Even within this restricted range of language experience, subjects with more years of language experience-in both age groups tended to reach higher levels of awareness of Sillyspeak. Years of language study was positively correlated with level of awareness across all subjects $(r(78)=0.4 \mathrm{I}, p=.0 \mathrm{I})$.

This confound points to a direction for future research: ideally, research on implicit and explicit training conditions should compare adults who are truly naive language learners to children who are truly naive language learners. Failing that, children should be matched to adults for years and type of prior language instruction. The adults in the present study, being limited to no more than two years of prior foreign language instruction, are more naive than the participants of other prominent studies on implicit and explicit training conditions (DeKeyser, I995; Morgan-Short, 2007), but still less naive than the children.

The third research question asked whether awareness of the grammatical structures of a mini-language would be associated with higher performance in the language for children and for adults. There was no interaction between age group and awareness group. For both children and adults, participants who developed greater awareness of the mini-language's structures were also able to produce and judge sentences in the mini-language more accurately.

The last research question asked whether there would be within-group age-related differences in language performance or in awareness of grammatical structure. In general, results showed that older children performed better and were more aware than younger children, but that for adults, young adults tended to perform better than older adults, and to be more aware of structure. However, many of these trends were not very strong. Though adults always outperformed children, exact age within each group was not a strong predictor of performance or of awareness.

\section{CONCLUSION}

Many of the most interesting claims of the literature on implicit and explicit second language learning are about age effects: the idea that children have access to some sort of natural, intuitive, slow, but robust implicit language learning system, which is no longer available to adults, is intriguing. However, child L2 learners themselves have been left out of the research. In order to investigate age effects on second language acquisition, it is important to hold all other variables constant, including knowledge of a first language and learning environment. This study investigated age and 
learning environment independently by assigning children and adults to controlled implicit or explicit training conditions, and assessed the implicit and explicit knowledge of an artificial mini-language that they gained through that instruction.

The position I call the maturational hypothesis holds that children learn languages implicitly because of cognitive maturation-because they are children. If this is the case, children should not benefit from explicit training. Results, though, showed that children aged five to seven who received explicit training did develop more explicit knowledge of the mini-language's grammatical rules than those receiving implicit training, and that all children, even those not given explicit training, produced sentences more accurately when their attention was drawn to form. These results better fit the instructional hypothesis: children learn languages implicitly because they have not been exposed to explicit grammar instruction; adults learn languages explicitly because they have already been exposed to explicit grammar instruction.

As this was a short, seven-day study, adults outperformed children on all tasks, but this difference was quantitative, not qualitative. The one qualitative difference between adults and children was on metalinguistic awareness: some adults in the implicit training condition guessed the mini-language's rules, but no children in the implicit group guessed the rules. However, this was confounded with previous foreign language instruction: participants who had had closer to two years of previous foreign language instruction were more likely to reach the level of understanding the mini-language's rules. Thus, this difference between children and adults may also have an environmental component rather than being purely maturational. Some children in the implicit group did notice the structures of the mini-language within the seven days of the study. It is possible that the children might have reached the level of understanding the mini-language's structures given additional time (or not; cf. Ferman \& Karni, 2010); this is an empirical question that can be pursued in future work.

Other important directions for future investigation which could address limitations of the present study are how adults who had truly had no prior foreign language instruction would perform, particularly with regard to developing metalinguistic awareness in the absence of explicit instruction - and, conversely, whether children with more prior explicit foreign language instruction would be able to deduce grammatical structures without instruction. Additionally, replicating results with natural languages, longer periods of instruction, and more age groups between age five and adults is important in order to be able to further generalize the results of mini-language experiments. A reviewer points out that other tests, such as word monitoring or a visual world paradigm, could provide more on-line measures of implicit knowledge. 


\section{I C H T MAN}

Overall, this study shows more similarities than differences between child and adult $\mathrm{L}_{2}$ learners. Both children and adults are capable of learning an artificial mini-language under either implicit or explicit training conditions. Both perform more accurately when their attention is drawn to form. Both develop more explicit knowledge when instructed explicitly (although adults may also develop explicit knowledge on their own). Both age groups make errors, displaying individual differences in performance.

The effects of training condition were seen most clearly in measures of awareness, not measures of language performance. This adds to the body of literature showing that implicit and explicit training conditions may be equally effective when participants are given time to reach proficiency and must process language in order to complete a task (Morgan-Short, 2007; Morgan-Short et al., 2010.)

These results do not support the idea that children, because of their cognitive maturation, rely on implicit learning mechanisms in all circumstances, nor that adults always rely on explicit learning mechanisms. Rather, they suggest that the learning environment is very important: explicit language instruction leads to explicit language knowledge, at any age. Adults, having had more lifetime exposure to explicit information about language, may be more likely than children to seek out and use explicit knowledge-without this difference being caused exclusively by cognitive maturation. This makes an important contribution to our understanding of age and second language acquisition. Relying on explicit knowledge and benefitting from explicit instruction may not be hallmarks of ADULT classroom L2 learning specifically, but rather hallmarks of classroom L2 learning at any age.

\section{REFERENCES}

Bialystok, E. (1994). Representation and ways of knowing: three issues in second language acquisition. In N. C. Ellis (ed.), Implicit and explicit learning of languages (pp. 549-69). San Diego, CA: Academic Press.

Birdsong, D. (ed.) ( 1989 ). Metalinguistic performance and interlinguistic competence (Vol. 25). London: Springer Science \& Business Media.

Bley-Vroman, R. ( I 990). The logical problem of foreign language learning. Linguistic Analysis 2o, 3-49.

Blom, E. (2008). Testing the domain-by-age model: inflection and placement of Dutch verbs. In B. Haznedar \& E. Gavruseva (eds), Current trends in child second language acquisition: a generative perspective (pp. 27I-300). Amsterdam/Philadelphia: Benjamins.

Curtain, H. \& Dahlberg, C. A. (2010). Languages and children: making the match. New languages for young learners, grades $K-8$. New York: Pearson.

de Graaf, R. (1997). The eXperanto eXperiment: effects of explicit instruction on L2 acquisition. Studies in Second Language Acquisition 19, 249-76.

DeKeyser, R. (1995). Learning second language grammar rules: an experiment with a miniature linguistic system. Studies in Second Language Acquisition I7, 379-410.

DeKeyser, R. (2000). The robustness of critical period effects in second language acquisition. Studies in Second Language Acquisition 22, 499-533. 
DeKeyser, R. (2003). Implicit and explicit learning. In C. Doughty \& M. Long (eds), Handbook of second language acquisition (pp. 31 3-48). Oxford: Blackwell.

DeKeyser, R., Alfi-Shabtay, I. \& Ravid, D. (2010). Cross-linguistic evidence for the nature of age effects in second language acquisition. Applied Psycholinguistics 3I(3), 4I 3-38.

DeKeyser, R. \& Larson-Hall, J. (2005) What does the critical period really mean? In J. F. Kroll \& A. M. D. De Groot (eds), Handbook of bilingualism: psycholinguistic approaches (pp. 88-108). Oxford: Oxford University Press.

Dunn, L. M. \& Dunn, D. M. (2007). Peabody Picture Vocabulary Test, 4 th edn (PPVT $\left.{ }^{\mathrm{TM}}{ }_{4}\right)$. Johannesburg: Pearson Education Inc.

Ebbels, S. (2007). Teaching grammar to school-aged children with specific language impairment using Shape Coding. Child Language Teaching and Therapy 23(I), 67-93.

Ellis, R. (2005). Measuring implicit and explicit knowledge of a second language: a psychometric study. Studies in Second Language Acquisition 27, I4I-72.

Ellis, R. (2009). Implicit and explicit learning, knowledge, and instruction. In R. Ellis, S. Loewen, C. Elder, R. Philp \& H. Reinders (eds), Implicit and explicit knowledge in second language learning, testing, and teaching (pp. 3-25). Buffalo: Multilingual Matters.

Ferman, S. \& Karni, A. (20I0). No childhood advantage in the acquisition of skill in using an artificial language rule. PLOS One $\mathbf{5}$ (10), I-Io.

Finestack, L. \& Fey, M. (2009). Evaluation of a deductive procedure to teach grammatical inflections to children with language impairment. American Fournal of Speech-Language Pathology 18, 289-302.

Harley, B., Howard, J. \& Hart, D. (1998). Grammar in grade 2: an instructional experiment in primary French immersion. In S. Lapkin (ed.), French second language education in Canada: empirical studies (pp. I77-93). Toronto: University of Toronto Press.

Housen, A. \& Pierrard, M. (2006). Investigating instructed second language acquisition. In A. Housen \& M. Pierrard (eds), Investigations in instructed second language acquisition (pp. I-27). Berlin: Mouton de Gruyter.

Hudson Kam, C. L. \& Newport, E. L. (2009). Getting it right by getting it wrong: when learners change languages. Cognitive Psychology 59, 30-66.

Jia, G. \& Aaronson, D. (2003). A longitudinal study of Chinese children and adolescents learning English in the United States. Applied Psycholinguistics 24(I), I3 I-6I.

Jia, G. \& Fuse, A. (2007). Acquisition of English grammatical morphology by native Mandarin-speaking children and adolescents: age-related differences. Fournal of Speech, Language, and Hearing Research 5o(5), i 280-99.

Johnson, J. \& Newport, E. (I989). Critical period effects in second language learning: the influence of maturational state on the acquisition of English as a second language. Cognitive Psychology 21, 60-99.

Krashen, S. D., Scarcella, R. C. \& Long, M. H. (eds) (I982). Child-adult differences in second language acquisition. Rowley, MA: Newbury House.

Larson-Hall, J. (2010). A guide to doing statistics in second language research using SPSS. New York: Routledge.

Lenneberg, E. H. (1967). Biological foundations of language. New York: Wiley.

Lichtman, K. (2013). Developmental comparisons of implicit and explicit language learning. Language Acquisition 20(2), 93-108.

Morgan-Short, K. (2007). A neurolinguistic investigation of late-learned second language knowledge: the effects of implicit and explicit conditions. Unpublished doctoral dissertation, Georgetown University.

Morgan-Short, K., Sanz, C., Steinhauer, K. \& Ullman, M. T. (20ro). Second language acquisition of gender agreement in explicit and implicit training conditions: an event-related potential study. Language Learning 6o(I), I 54-93.

Montrul, S. (2008). Incomplete acquisition in bilingualism: re-examining the age factor. Amsterdam: John Benjamins.

Muñoz, C. (2006). Age and the rate of foreign language learning. Buffalo: Multilingual Matters.

Muñoz, C. (2008). Age-related differences in foreign language learning: revisiting the empirical evidence. International Review of Applied Linguistics 46, I97-220. 


\section{I C H T MA N}

Norris, J. \& Ortega, L. (200I). Does type of instruction make a difference? Substantive findings from a meta-analytic review. Language Learning 5I, I 57-2 I 3.

Paradis, M. (2004). A neurolinguistic theory of bilingualism. Amsterdam: John Benjamins.

Paradis, M. (2009). Declarative and procedural determinants of second languages. Amsterdam/ Philadelphia: John Benjamins.

Rosa, E. \& Leow, R. (2004). Awareness, different learning conditions, and L2 development. Applied Psycholinguistics 25, 269-92.

Rosa, E. \& O'Neill, M. ( ( 999). Explicitness, intake, and the issue of awareness: another piece to the puzzle. Studies in Second Language Acquisition 215 I I-56.

Schmidt, R. W. (1990). The role of consciousness in second language learning. Applied Linguistics II I 29-58.

Schmidt, R. W. (I994). Implicit learning and the cognitive unconscious: of artificial grammars and SLA. In N. Ellis (ed.), Implicit and explicit learning of languages (22) (pp. I65-209). London: Academic Press.

Schwartz, B. D. (2004). Why child L2 acquisition? In J. Van Kampen \& S. Baauw (eds), Proceedings of Generative Approaches to Language Acquisition 2003 (pp. 47-66). Utrecht: LOT Occasional Series.

Singleton, D. \& Ryan, L. (2004). Language acquisition: the age factor. Buffalo : Multilingual Matters.

Spada, N. \& Tomita, Y. (2010). Interactions between type of instruction and type of language feature: a meta-analysis. Language Learning 6o(2), 263-308.

Swisher, L. \& Restrepo, M. A. (I995). Effect of implicit and explicit 'rule' presentation on bound-morpheme generalization in specific language impairment. Fournal of Speech $\Xi^{\circ}$ Hearing Research 38(1), I68-1 73 .

Torras, M. R., Navés, T., Luz Celaya, M. \& Pérez-Vidal, C. (2006). Age and interlanguage development in writing. In C. Muñoz (ed.), Age and the rate of foreign language learning (pp. I 56-82). Buffalo: Multilingual Matters.

Ullman, M. T. (200I). The neural basis of lexicon and grammar in first and second language: the declarative/procedural model. Bilingualism: Language and Cognition 4(2), I05-22.

Unsworth, S. (2005). On the syntax-semantics interface in Dutch: adult and child L2 acquisition compared. International Review of Applied Linguistics 42(4), I 73-87.

Zdorenko, T. \& Paradis, J. (20I I). Articles in child L2 English: when LI and L2 acquisition meet at the interface. First Language I, I-25. 